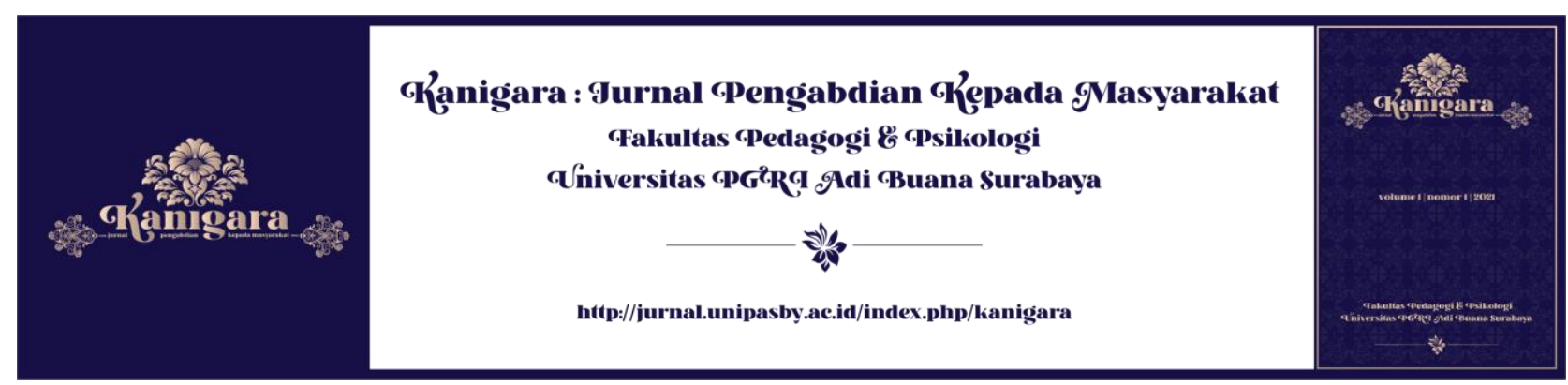

\title{
WORKSHOP PENYUSUNAN DAN PENILAIAN SOAL BERBASIS HOTS PADA PEMBELAJARAN GURU MATEMATIKA
}

\author{
Suyanto ${ }^{1}$, Arie Purwa Kusuma ${ }^{2}$, Nurina Kurniasari Rahmawati ${ }^{3}$, Fiki Alghadari ${ }^{4}$ \\ Prodi Pendidikan Matematika STKIP Kusuma Negara \\ *Email: arie_pk@stkipkusumanegara.ac.id ${ }^{1}$
}

\begin{tabular}{l}
\hline Informasi Artikel \\
\hline \hline $\begin{array}{l}\text { Kata kunci: } \\
\text { penilaian soal, HOTS, } \\
\text { guru Matematika }\end{array}$ \\
Diterima: $16-01-2021$ \\
Disetujui: $20-01-2021$ \\
Dipubikasikan: 26-01- \\
2021
\end{tabular}

Abstrak

Kegiatan workshop ini adalah bagian dari pengabdian masyarakat yang dilatarbelakangi oleh berkembangnya soal berbasis HOTS, Salah satu perkembangan dari sistem penilaian pendidikan di Indonesia saat ini adalah diterapkannya penilaian berbasis HOTS (Higher Order Thinking Skill). Kurikulum untuk matematika sekolah menengah telah berubah pada pengembangan berpikir HOTS. Selain itu juga untuk meningkatkan wawasan, inovatif dan ketrampilan guru-guru MTS Penerapan penilaian soal berbasis HOTS bertujuan agar proses pembelajaran khususnya matematika dapat mendorong siswa mengembangkan kemampuan berfikir kreatif. Metode pelaksanaan program adalah melakukan pengenalan HOTS, penyusnan HOTS dan penilaian soal HOTS. Kegiatan ini dilakukan kepada guru-guru MTs Se-Kota Bekasi. Dari hasil pelaksanaan kegiatan pengabdian kepada masyarakat ini, diperoleh hasil bahwa: (1) Bertambahnya wawasan guru-guru Se-Kota Bekasi tentang pembelajaran Matematika inovatif yang berbasis HOTS, (2) Meningkatnya pemahaman guru-guru MTS Se-Kota Bekasi dalam memecahkan masalah Matematika yang menuntut berpikir tingkat tinggi yang berbasis HOTS.

\begin{tabular}{l}
\hline Abstact \\
Kegiatan workshop ini adalah bagian dari pengabdian masyarakat yang \\
dilatarbelakangi oleh berkembangnya soal berbasis HOTS, Salah satu \\
perkembangan dari sistem penilaian pendidikan di Indonesia saat ini adalah \\
diterapkannya penilaian berbasis HOTS (Higher Order Thinking Skill). \\
Kurikulum untuk matematika sekolah menengah telah berubah pada \\
pengembangan berpikir HOTS. Selain itu juga untuk meningkatkan \\
wawasan, inovatif dan ketrampilan guru-guru MTS Penerapan penilaian \\
soal berbasis HOTS bertujuan agar proses pembelajaran khususnya \\
matematika dapat mendorong siswa mengembangkan kemampuan berfikir \\
kreatif. Metode pelaksanaan program adalah melakukan pengenalan HOTS, \\
penyusnan HOTS dan penilaian soal HOTS. Kegiatan ini dilakukan kepada \\
guru-guru MTs Se-Kota Bekasi. Dari hasil pelaksanaan kegiatan pengabdian \\
kepada masyarakat ini, diperoleh hasil bahwa: (1) Bertambahnya wawasan \\
guru-guru Se-Kota Bekasi tentang pembelajaran Matematika inovatif yang \\
berbasis HOTS, (2) Meningkatnya pemahaman guru-guru MTS Se-Kota \\
Bekasi dalam memecahkan masalah Matematika yang menuntut berpikir \\
tingkat tinggi yang berbasis HOTS.
\end{tabular}




\section{PENDAHULUAN}

Pendidikan menjadi parameter dalam kemajuan suatu bangsa yang menjadi sangat penting. Pendidikan merupakan tolak ukur kemajuan suatu bangsa. Pendidikan di Indonesia masih belum berhasil menciptakan sumber daya manusia yang profesional serta dalam taraf meningkatkan kualitas bangsa. Krisis multi dimensi yang dialami bangsa ini diyakini oleh banyak kalangan akibat gagalnya sistem pendidikan yang digunakan. Bidang pendidikan merupakan komponen yang sangat penting sebagai salah satu penentu suksesnya pembangunan nasional. Peningkatan sumber daya manusia dilakukan dalam wahana dunia pendidikan terutama melalui jenjang-jenjang pendidikan formal, mulai tingkat TK, pendidikan dasar (SD dan SMP), menengah (SMA atau SMK), sampai jenjang perguruan tinggi.

Perkembangan ilmu pengetahuan dan teknologi saat ini menuntut manusia untuk memiliki berbagai kemampuan guna menghadapi masa depan diantaranya adalah keterampilan abad 21 yang terdiri dari berfikir kritis, kreatif, inovasi, komunikasi dan kolaborasi (Redhana, 2019). Kurikulum 2013 disusun untuk meningkatkan keterampilan abad 21 menuntut guru agar berperan penting dalam melatih siswa mengembangkan keterampilan berfikir tingkat tinggi (Yuliandini, N., Hamdu, G., \& Respati, R. (2019). Siswa diharapkan tidak hanya mengetahui dan memahami sebuah pengetahuan tetapi juga dapat menganalisis, mengevaluasi bahkan menciptakan sesuatu dari pemanfaatan pengetahuan yang dimiliki.

Matematika merupakan ilmu yang didasari konsep abstrak sehingga pemberian materi pelajaran ini dapat dilakukan dengan cara mengaitkan materi dengan kehidupan sehari - hari (Dinni, 2018). Hal ini dilakukan supaya siswa mampu menemukan konsep dari pengalaman di lingkungan sekitar. Matematika tidak hanya berorientasi pada penguasaan konsep atau fakta melainkan lebih kepada kemampuan untuk berfikir kreatif mengaplikasikan pengetahuan dasar yang dimilikinya untuk menyelesaikan sebuah permasalahan (Sumaryanta, 2018). Permasalahan yang dimaksud tentunya bukan berupa soal yang biasa disajikan tetapi juga termasuk soal atau masalah - masalah yang berbeda dari soal pada umumnya. Kemampuan siswa mengkaji suatu masalah dan mngaitkannya dengan konsep yang telah dimiliki inilah yag disebut dengan kemampuan berfikir tingkat tinggi atau Higher Order Thinking Skill (Wardani \& Juniarso, 2019).

Pergeseran dalam pembelajaran dan penilaian dengan mengadopsi praktik HOTS merupakan alur peningkatkan kualitas pendidikan yang memiliki standar internasional. Untuk mencapai tujuan ini, Ganapathy dan Kaur (2014) berpendapat bahwa semua guru harus memastikan bahwa penilaian kelas dan pembelajaran harus fokus pada elemen HOTS. Namun, Zhang dan Judith (2003) dan Juniarso (2018) menyarankan agar setiap tes atau penilaian yang dilakukan oleh guru perlu memiliki kesinambungan dengan proses belajar. Puspendik (2016) 
secara sederhana menyebutkan bahwa High Order Thinking Skills (HOTS) atau kemampuan berfikir orde lebih tinggi adalah kemampuan berfikir yang tidak sekedar mengingat (recall), menyatakan kembali (restate), atau merujuk tanpa melakukan pengolahan (recite). Kemampuan yang diujikan pada higher order thinking skills antara lain; 1) transfer satu konsep ke konsep lainnya, 2) memproses dan menerapkan informasi, 3) mencari kaitan dari berbagai informasi yang berbeda-eda, 4) menggunakan informasi untuk menyelesaikan masalah, dan 5) menelaah ide dan informasi secara kritis. Beberapa penelitian membuktikan bahwa banyak guru belum dapat membuat soal HOTS. Nadila (2018) dalam penelitiannya menemukan bahwa tes yang dibuat oleh guru banyak bergantung pada soal LOTS (ditafsirkan sebagai pengetahuan, pemahaman dan aplikasi dalam Bloom Taksonomi). Setelah ditelaah dan dianalisis, ditemukan bahwa secara konsisten di semua kelas lebih dari 90\% dari item tes yang diukur merupakan soal LOTS. Selain itu ditemukan juga bahwa ketika guru matematika secara khusus diminta untuk menulis soal HOTS, enam puluh persen dari guru membuat soal yang berkategori LOTS.

Mempertimbangkan pentingnya HOTS dan banyaknya guru matematika MTs di Kota Bekasi yang banyak sekali belum memahami tentang penyusunan dan penilaian soal berbasis HOTS, maka tim dari program studi pendidikan Matematika STKIP Kusuma Negara perlu melakukan kegiatan Pengabdian kepada Masyarakat melalui kegiatan pelatihan dengan tema Konstruksi Tes High Order Thinking Skills (HOTS) Matematika MTs yang dilakukan kepada para guru matematika di kota Bekasi.

\section{METODE}

Subyek Pengabdian ini adalah seluruh guru MTs pada mata pelajaran matematika se-Kota Bekasi, yang dilaksanakan di MTs Negeri 1 Kota Bekasi dalam kegiatan MGMP mata pelajaran matematika Madrasah Tsanawiyah Negeri dan Swasta Se-Kota Bekasi. Tahapan pada kegiatan ini meliputi tahap perencanaan, persiapan dan pelaksanaan. Secara umum dapat dijelaskan sebagai berikut:

\section{Perencanaan}

Kegiatan awal diskusi dengan ketua MGMP Kota Bekasi tentang masalah-masalah yang di hadapi oleh para guru matematika terutama tentang soal matematika berbasis HOTS. Sebagian besar guru masih kesulitan untuk menentukan dan membuat soal yang berbasis HOTS.

2. Pelaksanaan

Pelaksanaan Tim PKM dengan 3 Dosen dan dibantu oleh 1 Mahasiswa dan 1 Alumni. Pada hari Senin, 11 November 2019. 


\section{Pelaksanaan Kegiatan}

Kegiatan pengabdian kepada masyarakat oleh tim prodi pendidikan matematika STKIP Kusuma Negara dilaksanakan dalam 3 Sesi. Sesi I berupa kegiatan pengenalan HOTS, Sesi II berupa kegiatan penelaahan soal HOTS dan Sesi III Pembuatan Soal HOTS dan Penilaian Soal HOTS.

Peserta yang terlibat dalam kegiatan ini yaitu guru-guru matematika Madrasah Tsanawiyah Negeri dan Swasta Se-Kota Bekasi, dengan jumlah peserta 42 Orang Pelaksanaan kegiatan ini terdiri dari dua tahap. Tahap I meliputi kegiatan penyampaian materi. Sedangkan tahap II diskusi dan tanya jawab.

\section{Sesi I}

Pada tahap ini penyuluhan tentang HOTS, bagaiman peranan soal berbasis HOTS dalam pembelajaran matematika saat ini. Apa perbedaan antara LOTS dan HOTS.

\section{Sesi II}

Pada tahap ini pengenalan bentuk-bentuk soal yang berbasis HOTS, membedakan bentuk soal LOTS dan HOTS, ciri-ciri soal HOTS dan kisi-kisi instrumen soal HOTS .

\section{Sesi III}

Pada tahap ini menerangkan tentang pembuatan Soal HOTS dan Penilaian Soal HOTS. Kemudian dilanjutkan latihan pembuatan soal oleh masing-masing peserta.

\section{HASIL DAN PEMBAHASAN}

Berdasarkan dari hasil pelaksanaan kegiatan yang sudah berlangsung, dapat digambarkan bagaimana pelaksanaan pengabdian pada masyarakat ini tidak lepas dari faktor pendukung dan faktor penghambat. Semangat para peserta yang meruapakan para guru-guru matematika ini sangat luarbiasa terlihat dari jumlah kehadiran peserta yang sangat banyak. Semangat para guru untuk mengikuti pelatihan sangat tinggi, terlepas dari itu juga terdapat faktor penghabat yaitu tersedianya waktu dalam pelaksanaan kegiatan oelatihan tersebut yang tentunya menjadi bahan evaluasi tim pengabdian pada masyarakat diperiode berikutnya. 


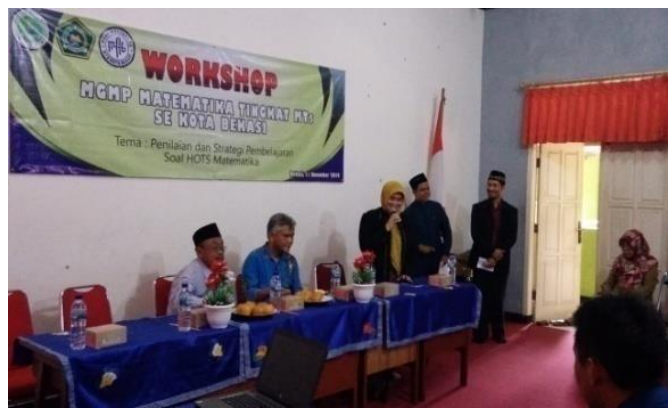

Gambar 1. Pemanyajian materi

Kegiatan pada tahap 1, pemateri menyampaikan tentang peranan soal HOTS.

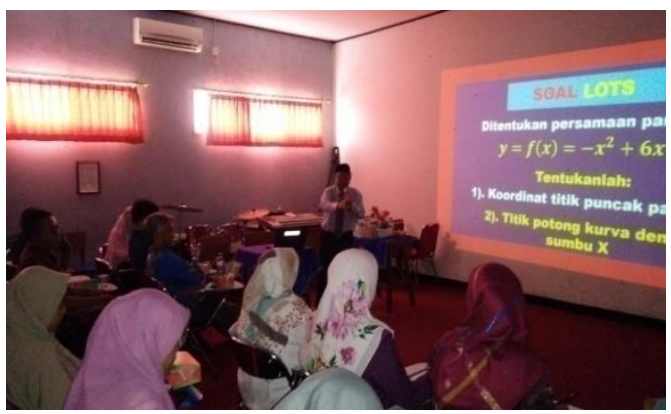

\section{Gambar 2. Pemaparan Soal HOTS}

Kegiatan pada tahap 2 yaitu memaparkan soal yang berbasis HOTS, membedakan bentuk soal LOTS dan HOTS, ciri-ciri soal HOTS dan kisi-kisi instrumen soal HOTS.

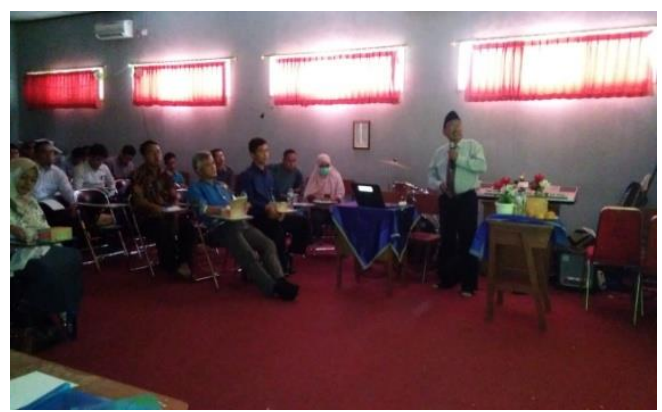

Gambar 3. Pembuatan instrument Soal HOTS

Kegiatan pada tahap 3 ini menerangkan tentang pembuatan Soal HOTS dan Penilaian Soal HOTS. Kemudian dilanjutkan latihan pembuatan soal oleh masing-masing peserta.

Hasil yang dcapai dari kegiatan pengabdian kepada masyarakat ini adalah meningkatnya kemampuan dan ketrampilan guru MTs se Kota Bekasi dalam penyusunan perangkat soal HOTS (Higher Order Thinking Skills). Hal ini berdasarkan evaluasi dan simulasi pada pelatihan dari kegiatan pengabdian kepada masyarakat dapat diketahui bahwa yang semula peserta belum memahami dan terampil dalam menyusun perangkat perangkat soal HOTS, maka setelah kegiatan 
kemampuan dan ketrampilan guru meningkat. Guru dapat mengerti dan memahami kriteriakriteria dalam penyusunan perangkat soal HOTS dan kemampuan penyusunan perangkat soal HOTS juga menjadi lebih baik dan berkualitas. Dengan jumlah peserta 48 yang hadir, Hal tersebut menunjukkan bahwa guru-guru antusias untuk mengikuti kegiatan pengabdian masyarakat. Hal ini dirasa cukup berhasil mengingat bahwa guru yang hadir melebihi target.

Penyusunan pengembangan soal HOTS serta soal tes menjadi lebih mengarah atau berorientasi pada keterampilan berpikir tingkat tinggi. Hal ini dirasa cukup berhasil mengingat guru MTS Kota Bekasi merupakan guru-guru yang selalu ingin maju dan meningkatkan kualitas diri. Diharapkan setelah kegiatan ini pada tahun ajaran berikutnya akan ada program kerja yang berisi kegiatan pelatihan yang terkait dengan teknik yang baik, mudah, dan efektif sesuai dengan kriteria kurikulum 2013 sebagai pelatihan lanjutan yang cukup diminati oleh para guru.

\section{KESIMPULAN}

Berdasarkan dari hasil kegiatan pelatihan penyusunan dan penilaian soal berbasis HOTS dapat disimpulkan bahwa para guru dapat memahi pengertian HOTS serta mampu membedakan soal yang berbasis HOTS dan selanjutnya mampu menyusun soal dan melakukan penilaian terhadap soal berbasis HOTS. Selain itu, respon guru terhadap kegiatan pelatihan ini sangat baik, yang artinya hasil pelaksanaan pengabdian masyarakat ini diterima dengan baik.

\section{DAFTAR PUSTAKA}

Ariyana, Y., \& Bestary, R. (2018). Buku Pegangan Pembelajaran Berorientasi pada Keterampilan Berpikir Tingkat Tinggi. Direktorat Jenderal Guru dan Tenaga Kependidikan Kementerian Pendidikan dan Kebudayaan Hak.

Brookhart, S.M. (2010). How to assess higher order thinking skills in your classroom. Alexandria: ASCD

Dinni, H. N. (2018). HOTS ( High Order Thinking Skills ) dan Kaitannya dengan Kemampuan Literasi Matematika. Prisma, 1, 170-176.

Fanani, M. Z. (2018). Strategi Pengembangan Soal HOTS Pada Kurikulum 2013. EDUDEENA, 2(1), 59-76.

Ganapathy, M., \& Kaur, S. (2014). ESL students' perceptions of the use of Higher Order Thinking skills in English language writing. Advances in Language and Literary Studies, 5(5), 80-87.

Hidayati, A. U. (2017). Melatih Keterampilan Berpikir Tingkat Tinggi Dalam Pembelajaran Matematika Pada Siswa Sekolah Dasar. TERAMPIL Jurnal Pendidikan Dan Pembelajaran Dasar, 4(20), 143-156.

Juniarso, T. (2018). Keefektifan Model Pembelajaran Brain Based Learning Terhadap High Order Thinking Skills (HOTS) Mahasiswa PGSD UNIPA Surabaya. MUST: Journal of Mathematics Education, Science and Technology, 3(2), 240-248.

Redhana, I. W. (2019). Mengembangkan Keterampilan Abad Ke-21 Dalam Pembelajaran Kimia. Jurnal Inovasi Pendidikan Kimia, 13(1). 
Sofyan, F. A. (2019). Implementasi Hots Pada Kurikulum 2013. Inventa, 3(1), 1 - 9. https://doi.org/10.36456/inventa.3.1.1803.

Sumaryanta. (2018). Penilaian HOTS dalam Pembelajaran Matematika. Indonesian Digital Journal of Mathematics and Education, 8(8), 500-509. https://doi.org/10.31227/osf.io/zypex

Wardani, I. S., \& Juniarso, T. (2019). The Effect Of Brain Based Learning Model On Student's High Order Thinking Skills. EduHumaniora| Jurnal Pendidikan Dasar Kampus Cibiru, 11(1), 71-74.

Yuliandini, N., Hamdu, G., \& Respati, R. (2019). Pengembangan Soal Tes Berbasis Higher Order Thinking Skill (HOTS) Taksonomi Bloom Revisi di Sekolah Dasar. PEDADIDAKTIKA: Jurnal Ilmiah Pendidikan Guru Sekolah Dasar, 6(1), 37-46.

Zhang, Z. dan Judith, A. B. (2003). Classroom Assessment Practices and Teachers' Self Perceived Assessment Skills. Applied Measurement in Education. 16(4), 323-342 